BNL-112668-2016-JA

\title{
Directed Self-assembly of Block Copolymers for High Breakdown Strength Polymer Film Capacitors
}

\author{
Saumil P. Samant, Christopher A. Grabowski, Kim Kisslinger, \\ Kevin G. Yager, Guangcui Yuan, Sushil K. Satija, Michael F. \\ Durstock, Dharmaraj Raghavan, Alamgir Karim
}

Submitted to ACS Applied Materials \& Interfaces

March 2016

Center for Functional Nanomaterials

Brookhaven National Laboratory

\author{
U.S. Department of Energy \\ USDOE Office of Science (SC), \\ Basic Energy Sciences (SC-22)
}

Notice: This manuscript has been authored by employees of Brookhaven Science Associates, LLC under Contract No. DE- SC0012704 with the U.S. Department of Energy. The publisher by accepting the manuscript for publication acknowledges that the United States Government retains a non-exclusive, paid-up, irrevocable, world-wide license to publish or reproduce the published form of this manuscript, or allow others to do so, for United States Government purposes. 


\section{DISCLAIMER}

This report was prepared as an account of work sponsored by an agency of the United States Government. Neither the United States Government nor any agency thereof, nor any of their employees, nor any of their contractors, subcontractors, or their employees, makes any warranty, express or implied, or assumes any legal liability or responsibility for the accuracy, completeness, or any third party's use or the results of such use of any information, apparatus, product, or process disclosed, or represents that its use would not infringe privately owned rights. Reference herein to any specific commercial product, process, or service by trade name, trademark, manufacturer, or otherwise, does not necessarily constitute or imply its endorsement, recommendation, or favoring by the United States Government or any agency thereof or its contractors or subcontractors. The views and opinions of authors expressed herein do not necessarily state or reflect those of the United States Government or any agency thereof. 


\section{Directed Self-assembly of Block Copolymers for}

\section{High Breakdown Strength Polymer Film Capacitors}

Saumil P. Samant, ${ }^{\dagger}$ Christopher A. Grabowski, ${ }^{\dagger}$ Kim Kisslinger, ${ }^{\#}$ Kevin G. Yager, ${ }^{\#}$ Guangcui Yuan, ${ }^{\S}$ Sushil K. Satija, ${ }^{\S}$ Michael F. Durstock, ${ }^{\dagger}$ Dharmaraj Raghavan, $\wedge$ Alamgir Karim ${ }^{\dagger} *$

$\dagger$ Department of Polymer Engineering, University of Akron, Akron, OH-44325, USA.

† Air Force Research Laboratory, Wright Patterson Air Force Base, Dayton, OH-45433, USA.

\# Center for Functional Nanomaterials, Brookhaven National Laboratory, Upton, NY-11973, USA.

$\S$ Center for Neutron Research, National Institute of Standards and Technology (NIST), Gaithersburg, MD-20899, USA .

^ Department of Chemistry, Howard University, Washington D.C.-20059, USA.

Keywords: block copolymer, directed self-assembly, Cold Zone Annealing-Soft Shear, lamellae, breakdown strength, barrier effect, dielectric, capacitor. 


\section{ABSTRACT}

Emerging needs for fast charge/discharge yet high-power, lightweight and flexible electronics requires the use of polymer film based solid-state capacitors with high energy densities. Fast charge/discharge rates of film capacitors on the order of microseconds are not achievable with slower charging conventional batteries, super-capacitors and related hybrid technologies. However, the current energy densities of polymer film capacitors fall short of rising demand, and could be significantly enhanced by increasing the breakdown strength $\left(E_{\mathrm{BD}}\right)$ and/or dielectric permittivity $\left(\varepsilon_{\mathrm{r}}\right)$ of the polymer films. Co-extruded two-homopolymer component multilayered films have demonstrated much promise in this regard showing higher $E_{\mathrm{BD}}$ over that of component polymers. Multilayered films can also help incorporate functional features besides energy storage, such as enhanced optical, mechanical, thermal and barrier properties. In this work, we report accomplishing multilayer, multicomponent block copolymer dielectric films (BCDF) with soft-shear driven highly oriented self-assembled lamellar diblock copolymers (BCP) as a novel application of this important class of self-assembling materials. Results of a model PS- $b$-PMMA system show $\sim 50 \%$ enhancement in $E_{\mathrm{BD}}$ of self-assembled multilayer lamellar BCP films compared to unordered as-cast films, indicating that the breakdown is highly sensitive to the nanostructure of the BCP. The enhancement in $E_{\mathrm{BD}}$ is attributed to the 'barrier effect' where the multiple interfaces between the lamellae block components act as barriers to the dielectric breakdown through the film. The increase in $E_{\mathrm{BD}}$ corresponds to more than doubling the energy storage capacity using a straightforward directed self-assembly strategy. This approach opens a new nanomaterial paradigm for designing high energy density dielectric materials. 


\section{Introduction}

Energy storage is a fundamental issue driving the development of new materials and their associated processing and fabrication into devices remains a major challenge in energy research today. Among the various energy storage technologies are batteries, fuel cells, supercapacitors and solid-state film capacitors. While batteries and fuel cells have high energy-storage capacities, they are bulky and not suitable for high-power applications due to very slow charge-discharge characteristics. Supercapacitors have moderate energy densities but low operating voltages and high leakage currents limit their application in pulsed power systems. In contrast, electrostatic or solid-state film capacitors possess the advantage of high power density due to relatively fast (ms$\mu \mathrm{s})$ energy storage and discharge rates. However, the energy storage density of these capacitors is limited by the dielectric properties of the materials that separate the oppositely charged electrodes, falling significantly short of rising demand in advanced applications. ${ }^{1}$ There is a critical need to not only develop new dielectric materials, but also to control their morphologies at the nanoscale in ways that can significantly increase their energy storage capacity thereby reducing the size, weight, and cost of electronic devices and power systems. ${ }^{2}$ The maximum energy density $(U)$ that can be stored within a capacitor is governed by the product of dielectric permittivity $\left(\varepsilon_{\mathrm{r}}\right)$ and breakdown strength $\left(E_{\mathrm{BD}}\right)$ of the dielectric material:

$$
U=\frac{1}{2} \varepsilon_{0} \varepsilon_{\mathrm{r}} E_{\mathrm{BD}}^{2}
$$

where $\varepsilon_{0}\left(8.85 \times 10^{-12} \mathrm{~F} / \mathrm{m}\right)$ is the permittivity of free space.

Polymer films are widely used as capacitor dielectric materials due to their desirable properties such as high $E_{\mathrm{BD}}$, low loss, flexibility, solvent processability, and graceful failure as opposed to the catastrophic failure of ceramic insulators. ${ }^{3-5}$ Commercially available capacitors most 
frequently employ semicrystalline biaxially oriented polypropylene (BOPP) films, which features a theoretical maximum energy storage of $\sim 4 \mathrm{~J} / \mathrm{cm}^{3}$, while fully packaged BOPP capacitors exhibit storage in the $1-2 \mathrm{~J} / \mathrm{cm}^{3}$ range. This energy density falls short of current demands, thus requiring enhancement in $\varepsilon_{\mathrm{r}}$ and/or $E_{\mathrm{BD}}$. Although significant efforts have been made to increase the $\varepsilon_{\mathrm{r}}$ of polymer film capacitors using nanocomposites or nanodielectrics, ${ }^{1,6-10}$ enhancement of $E_{\mathrm{BD}}$ without the use of fillers has not received similar attention. As seen from Equation (1), the energy density has a quadratic dependence on $E_{\mathrm{BD}}$ and thus enhancement of $E_{\mathrm{BD}}$ holds great potential for improving the current energy densities of polymer film capacitors.

In polymers, dielectric breakdown is traditionally assumed to occur by an electron avalanche mechanism via formation and propagation of electrical trees that resemble fractal conducting channels within the material. ${ }^{11,12}$ These electrical trees are initiated by structural defects in the material and propagate between the electrodes leading to breakdown. If the propagation of these electrical trees is impeded by a barrier, the breakdown process can be forestalled, thus enhancing the overall dielectric strength. This 'barrier effect' is a well-known concept applied in highvoltage engineering to increase the breakdown voltage. ${ }^{13-15}$ It is hypothesized that the presence of a barrier, i.e. a material of different permittivity or conductivity than the matrix, leads to formation of space charge near the interface on application of an external field, which causes redistribution of the field along the barrier-matrix interface. Vogelsang and coworkers have predicted using a deterministic model that the presence of a barrier (mica) significantly impedes the breakdown process in polymers (epoxy) as the electrical trees are forced along an extended tortuous pathway along the barrier-matrix interfaces. ${ }^{16,17}$ Pioneering work by Wolak and coworkers demonstrated the barrier effect in multilayered polymer films obtained using forced assembly multilayer coextrusion. ${ }^{2,18}$ By fabricating multi-layered PC-coPVDF composite films, a 
marked increase in the $E_{\mathrm{BD}}$ of multilayered films was observed over the expected linear weighted-average of individual polymer control films. Zhu and coworkers have further explored the multilayered co-extrusion, demonstrating that layered films have increased dielectric lifetimes as compared to blend films due to the barrier structure. ${ }^{19}$ Layered/interwoven architectures can also be generated through the dispersion and alignment of high aspect ratio, nanometer thick sheets of montmorillonite within a polymer matrix. The breakdown strength of such nanolaminates was found to increase by $30-50 \%$ relative to the unfilled polymer film. ${ }^{20,21}$

An undetermined issue with the coextruded multilayers is that of layer homogeneity due to spatial thickness variations, large micron-sized defects and layer delamination due to poor adhesion. In contrast to macroscopic processing, self-assembling polymer systems generate much more uniform and well-controlled nanostructured layers. In principle, self-assembled multilayered structures can be obtained using lamellae-forming symmetric block copolymer (BCP) films with the lamellar microdomains of the $\mathrm{BCP}$ aligned parallel to the substrate over large areas. To this end, we devised a novel strategy to create a polymer capacitor film having a highly ordered multilayered structure, with relatively defect-free, sharp nanoscale interfaces using directed self-assembly (DSA) methods applied to lamellae-forming BCP thick (>1 $1 \mu \mathrm{m})$ films. BCP films offer extraordinary tunability of dielectric contrast, orientation, layer thickness and interfacial width with self-assembly processes, from the intrinsic nanoscale molecular level to macroscopic thickness for device-level compatibility. While BCP self-assembly and resulting BCP-templated films have been extensively studied for many diverse electronic applications, ${ }^{22}$ the dielectric performance of self-assembled BCPs has not been explored and their use as the dielectric media in solid-state film capacitors has not been reported to date. In this paper, we report the very first application of self-assembled BCPs as potential solid-state capacitor 
materials and demonstrate that the dielectric strength $\left(E_{\mathrm{BD}}\right)$ is highly sensitive to the $\mathrm{BCP}$ nanostructure. These findings have significant ramifications in optimizing the breakdown strength of block copolymer structures and can guide future capacitor device development.

\section{Results and Discussion}

In thin $(<500 \mathrm{~nm})$ films, the parallel (to substrate) lamellar morphology can be readily achieved with simple uniform oven annealing in select low molecular weight BCP systems on preferential substrate surfaces. ${ }^{23-25}$ However, we have determined that highly ordered parallel lamellae could not be obtained with oven annealing for micron thick, high molecular weight BCP films on non-modified conductive substrates desired for capacitor studies (shown later). Instead, this can be potentially achieved using Directed Self-Assembly (DSA) techniques with high degree of directive forces applied to the BCP films. Most DSA methods employing solvent vapor $^{26}$, shear ${ }^{27,28}$, magnetic ${ }^{29}$ or electric fields ${ }^{30,31}$ are batch processes while others require topographical patterning ${ }^{32,33}$ or solvent immersion, such as the recently developed Direct Immersion Annealing (DIA) process. ${ }^{34}$ For large-area fabrication of capacitor films, it is useful to develop a DSA method that does not require substrate modification and is also compatible with roll-to-roll (R2R) processing. To this end, we employ a unique Cold Zone Annealing-Soft Shear (CZA-SS) method that was previously developed for unidirectional alignment of cylindrical block copolymer films. ${ }^{35-36}$ Herein, we demonstrate its novel application to fabricate highly ordered micron thick lamellar $\mathrm{BCP}$ dielectric films (BCDFs) aligned parallel to conductive Aluminum substrate for solid-state capacitor applications.

BCP Film Processing: The effect of a self-assembled multilayered lamellar structure on the breakdown properties was studied using the model BCP system polystyrene- $b$-poly (methyl 
methacrylate) (PS-b-PMMA), where the individual blocks have disparate dielectric breakdown values $(\mathrm{PS} \sim 250 \mathrm{~V} / \mu \mathrm{m}, \mathrm{PMMA} \sim 500 \mathrm{~V} / \mu \mathrm{m})$, but relatively close dielectric permittivity at 1 $\mathrm{kHz}$ [PS $\left(\varepsilon_{\mathrm{r}} \sim 2.6\right)$, PMMA $\left.\left(\varepsilon_{\mathrm{r}} \sim 3.2\right)\right]$. To elucidate the generality of the concept, we also studied another BCP system, polystyrene- $b$-poly (2-vinyl pyridine) (PS-b-P2VP), wherein the blocks have closer dielectric strength (PS $~ 250 \mathrm{~V} / \mu \mathrm{m}, \mathrm{P} 2 \mathrm{VP} \sim 380 \mathrm{~V} / \mu \mathrm{m}$ ), but much higher dielectric contrast [P2VP $\left.\left(\varepsilon_{\mathrm{r}} \sim 5\right)\right]$. Approximately $1 \mu \mathrm{m}$ thick BCP films of lamellae-forming PS-b-PMMA (19.5-b-18.1 kg mol ${ }^{-1}$ and $\left.33-b-33 \mathrm{~kg} \mathrm{~mol}^{-1}\right)$ and PS- $b-\mathrm{P} 2 \mathrm{VP}\left(25-b-25 \mathrm{~kg} \mathrm{~mol}^{-1}\right)$ were cast onto smooth aluminum-coated quartz substrates, which act as the bottom electrode, using a flowcoating technique (Supporting Information Figure S1). The films were then subjected to the CZA-SS process of directed self-assembly as detailed in a previous publication ${ }^{35}$ and Supporting Information. Briefly, a cross-linked PDMS pad is placed over the BCP films that are linearly translated over the cold block-hot wire-cold block CZA set-up as shown in Figure 1.a. The temperature of the hot $\operatorname{rod}\left(\mathrm{T}_{\max }\right)$ was set to $205{ }^{\circ} \mathrm{C}$ (well above the $T_{\mathrm{g}}$ of all polymers under investigation) whereas the cold blocks were kept at $26{ }^{\circ} \mathrm{C}$ giving an in-plane temperature gradient of $\sim 45^{\circ} \mathrm{C} / \mathrm{mm}$ as shown in Figure 1.b. The films were translated with a velocity of $\mathrm{V}=$ $5 \mu \mathrm{m} / \mathrm{s}$, which corresponds to a $T_{\mathrm{g}}$-to- $T_{\mathrm{g}}$ annealing time of 30 minutes on the temperature gradient curve. Since, the coefficient of thermal expansion of PDMS is about 4 times that of the BCP film (Figure 1.b), a thermal gradient-induced differential expansion and contraction of PDMS over the BCP results in a single oscillatory shear cycle, generating a shear stress of about $120 \mathrm{kPa}$ at the PDMS-BCP film interface. ${ }^{35}$ This shear stress directs the alignment of the BCP lamellae parallel to the substrate.

Morphology of BCP Films: By processing the film using CZA-SS, we obtain a completely parallel (to the substrate) lamellar morphology within the entire $\sim 1 \mu \mathrm{m}$ thick PS- $b$-PMMA film 
as shown in the cross-sectional TEM image in Figure 1.e. The dark phase in the TEM images corresponds to PS and light phase is the PMMA. For comparison, an "as-cast" film (no annealing) resembles a homogeneous single-phase morphology as illustrated in the crosssectional TEM image in Figure 1.c.

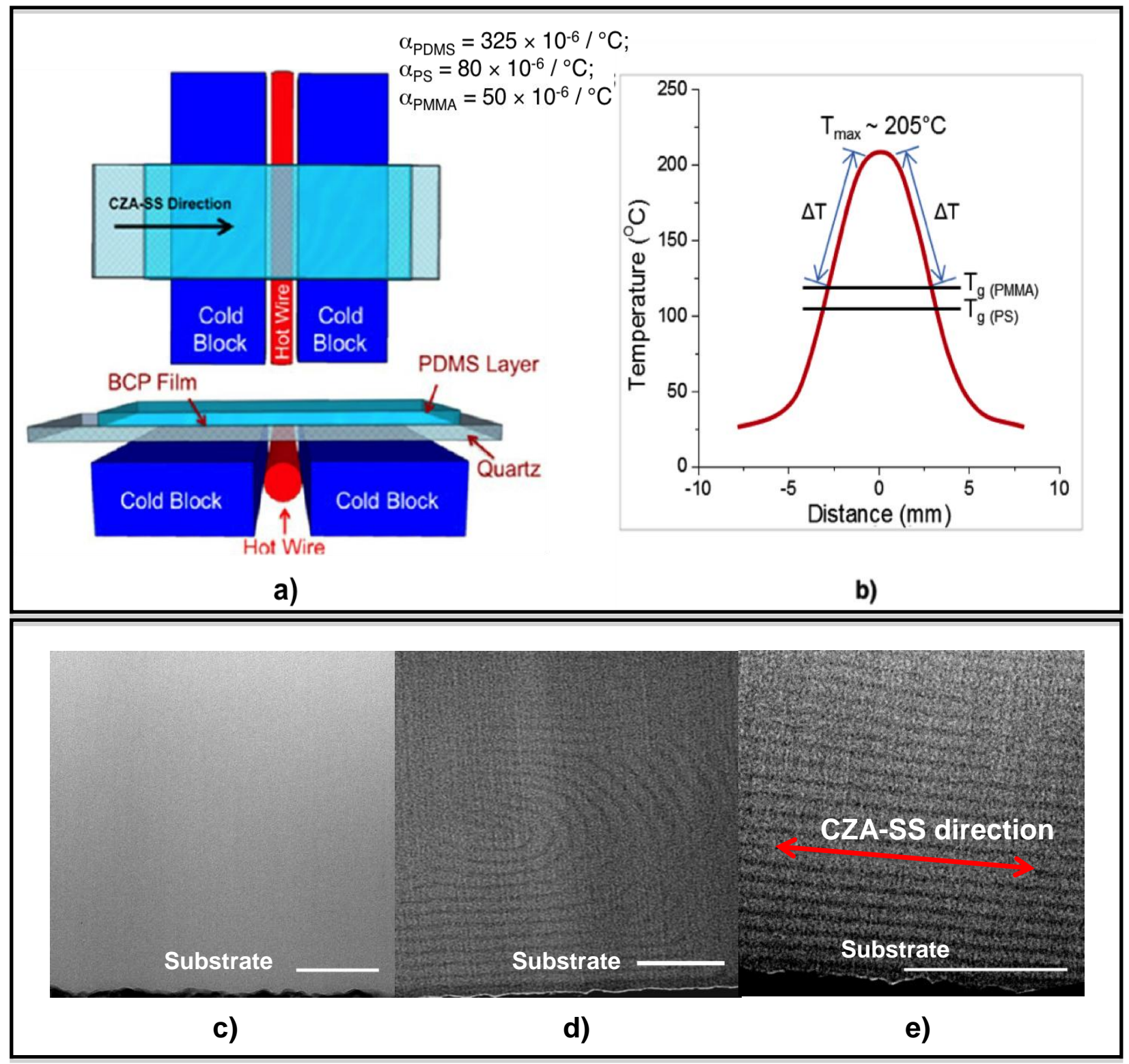

Figure 1. Thermal processing of BCP films and cross-sectional TEM imaging of PS-b-

PMMA films. a) Schematic for directed self-assembly of BCP film using Cold Zone AnnealingSoft Shear (CZA-SS). Reprinted with permission. ${ }^{35}$ Copyright (2012), American Chemical 
Society) b) Sharp thermal gradient profile induced by the CZA setup and linear thermal expansion coefficients of materials. Cross-sectional TEM images (no stain) of PS- $b$-PMMA (19.5-b-18.1 $\left.\mathrm{kg} \mathrm{mol}^{-1}\right)$ film on $\mathrm{Al}$ coated quartz substrate: c) as-cast, d) oven annealed for 96 hours at $205^{\circ} \mathrm{C}$ under vacuum and e) CZA-SS at $\mathrm{T}_{\max }=205^{\circ} \mathrm{C}, \mathrm{V}=5 \mu \mathrm{m} / \mathrm{s}$. (Scale bar: $0.2 \mu \mathrm{m}$ )

To underscore the importance of CZA-SS on BCP orientation and on the resulting breakdown properties, control samples were subjected to comparable thermal annealing at $205^{\circ} \mathrm{C}\left(\gg>\mathrm{T}_{\mathrm{g}}\right)$ in a vacuum oven and the morphologies were compared to CZA-SS samples. At relatively short times $(6 \mathrm{~h})$, the oven-annealed films exhibited predominantly perpendicular (to substrate) lamellar domains with some fraction of parallel lamellae near the substrate and air interfaces; at longer annealing times $(96 \mathrm{~h})$, the fraction of perpendicular lamellae decreased and parallel lamellar orientation dominated. This can be ascribed to the preferential wetting of PMMA on the substrate surface due to the polar interaction of PMMA with the native oxide surface on the Aluminum via the carbonyl bond $(-\mathrm{C}=\mathrm{O})$, similar to known interaction with $\mathrm{SiO}_{2}$ surface on silicon substrates, while the lower surface tension PS covers the film-air interface. ${ }^{24}$ This is followed by propagation of the surface interaction induced parallel lamellar ordering from both the substrate and air interface via thermal annealing. However, the strength of the surface interactions diminish with increasing distance and lead to mixed orientations away from the surfaces, especially in thick films. ${ }^{37}$ Hence, even after $96 \mathrm{~h}$ annealing, the lamellae did not orient completely parallel throughout the film, exhibiting some fraction of perpendicular lamellar component as seen in Figure 1.d.

The internal ordering and average interfacial structure within the CZA-SS processed films was further examined through neutron reflectivity (NR) studies on a deuterated BCP, dPS- $b$-PMMA $\left(19.5-b-18.1 \mathrm{~kg} \mathrm{~mol}^{-1}\right)$. The PS block is deuterated for neutron contrast; the self-assembly 
behavior of this $\mathrm{BCP}$ is essentially identical to its non-deuterated analogue. A NR curve of a CZA-SS processed film, along with a best fit, is shown in Figure 2.a.

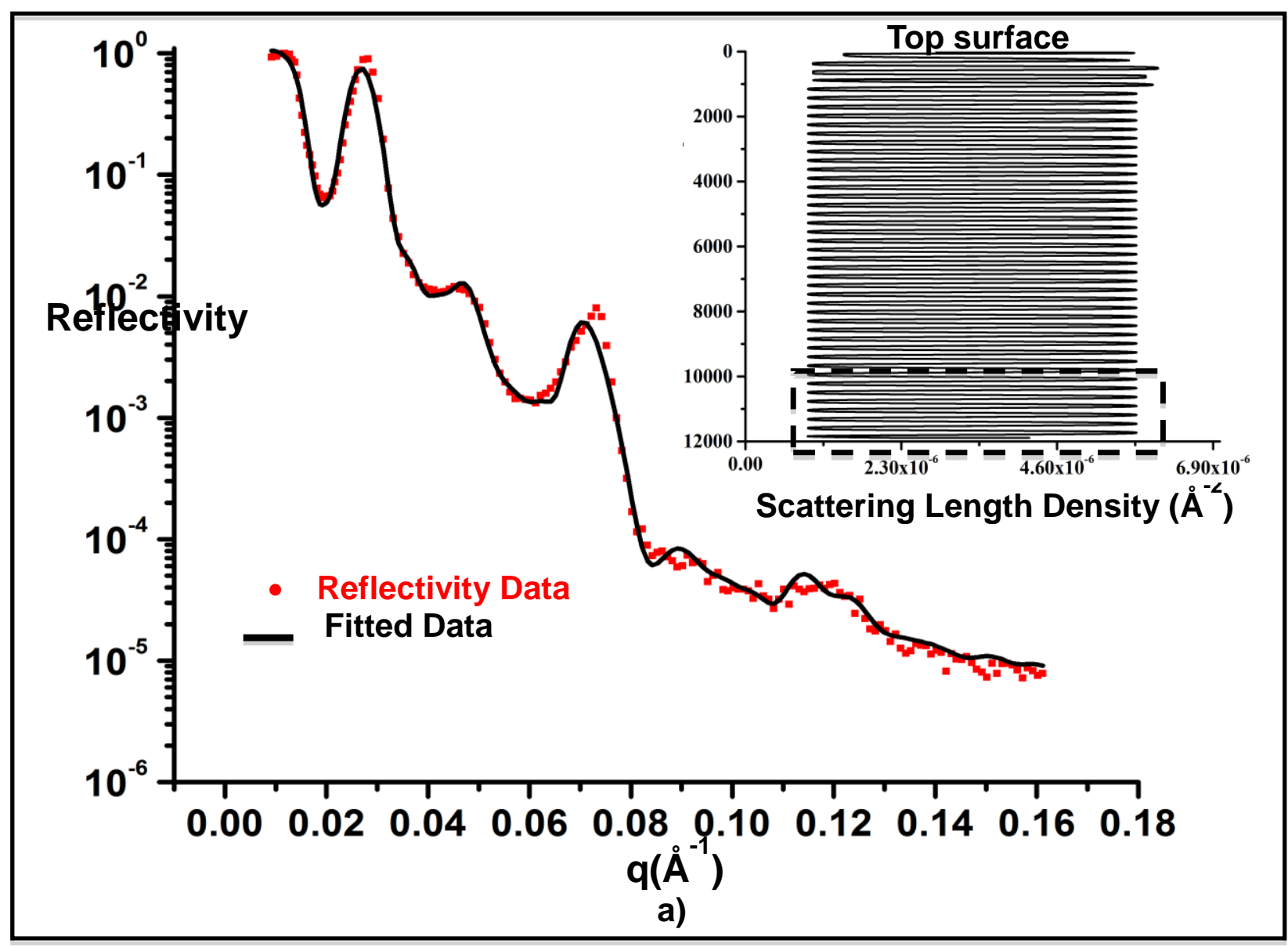




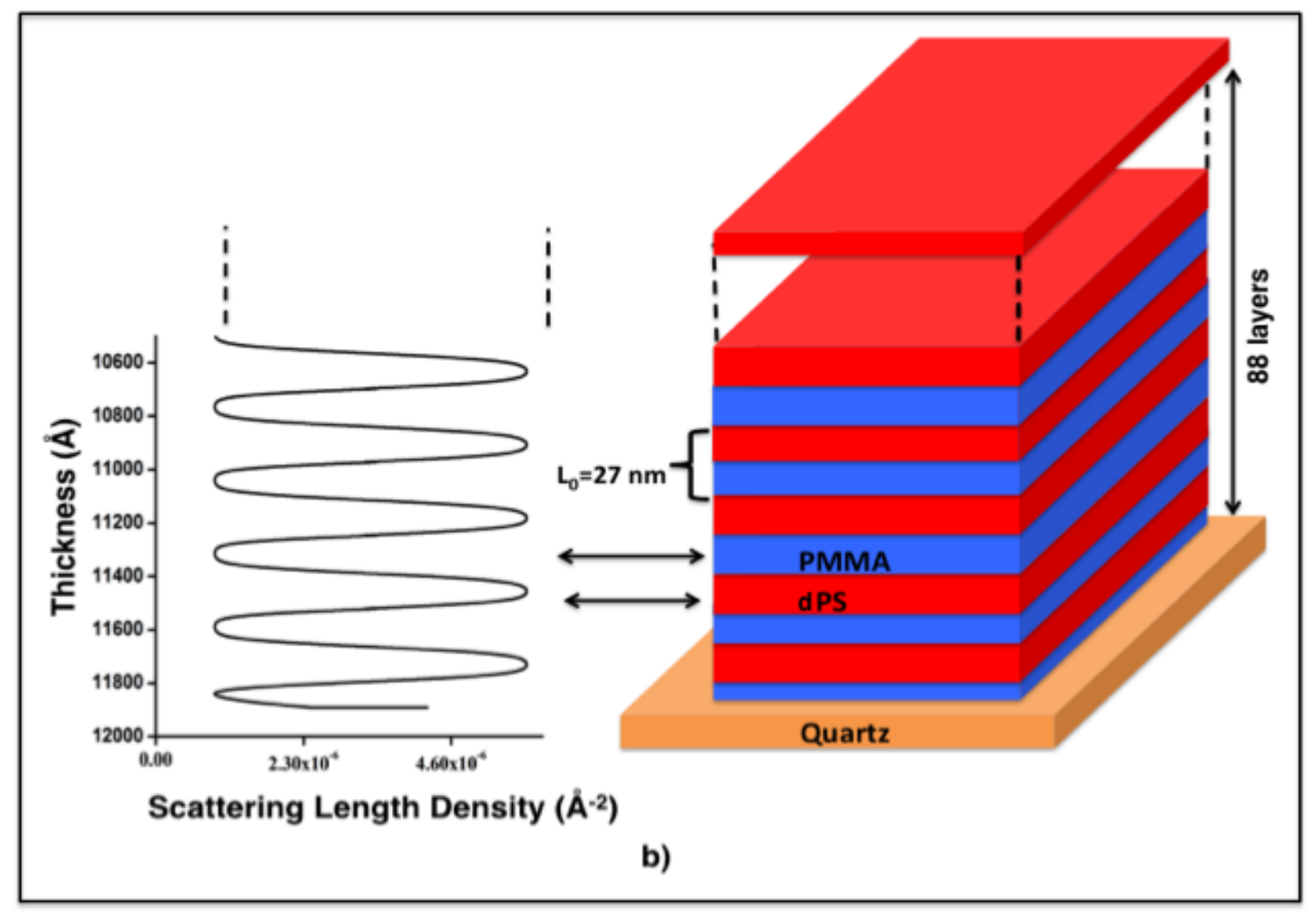

Figure 2. Neutron Reflectivity and composition profile of CZA-SS processed, highly ordered dPS-b-PMMA BCP film. a) Neutron Reflectivity (NR) data of CZA-SS processed dPS- $b$-PMMA (19.5-b-18.1 $\mathrm{kg} \mathrm{mol}^{-1}$ ) film (inset: Total layer composition profile normal to substrate). b) Enlarged layer composition profile (dashed area) near the substrate and profilebased schematic of the film structure.

Five orders of well-defined Bragg reflection peaks are seen, indicative of highly ordered parallel lamellar morphology; i.e. domains of dPS and PMMA alternating in the film normal direction. On fitting the data to a neutron scattering length density (SLD) profile, we obtain a composition profile normal to the substrate as seen in the inset of Figure 2.a. and enlarged in Figure 2.b. The film consists of appoximately 44 repeating units having an average width of 27 
$\mathrm{nm}$, which is comprised of a dPS $\left(\sim 13 \mathrm{~nm}, \mathrm{SLD} \sim 5.7 \times 10^{-6} \AA^{-2}\right)$ and PMMA $(\sim 14 \mathrm{~nm}, \mathrm{SLD} \sim$ $0.9 \times 10^{-6} \AA^{-2}$ ) block. The PMMA preferentially wets the native oxide-covered Aluminum substrate, while the lower surface tension of PS causes this material to cover the film/air interface. The best-fit profile also suggests a sharp average interfacial width of $\sim 5 \mathrm{~nm}$ between the PS and PMMA blocks, which is consistent with previous measurements of oven-annealed dPS- $b$-PMMA thin films studied by NR. ${ }^{23}$ Thus, NR confirms the CZA-SS driven highly ordered parallel lamellar orientation of BCP domains in the film, which resembles a multiple barrier structure consisting of 88 alternating PS and PMMA layers (Figure 2.b). To study the effect of molecular weight on the BCP ordering and subsequently on the breakdown characteristics, we used a higher molecular weight PS- $b$-PMMA (33- $\left.b-33 \mathrm{~kg} \mathrm{~mol}^{-1}\right) \mathrm{BCP}$.

Grazing-Incidence Small-Angle X-ray Scattering (GISAXS) experiments were performed in order to investigate the orientation and long-range ordering within the films under different processing conditions for all BCP systems under this study. The grazing-incidence angle $\left(0.18^{\circ}\right)$ was kept above the film critical angle $\left(0.16^{\circ}\right)$ thereby ensuring the measurement probes the entire film thickness. Two-dimensional GISAXS images and their corresponding intensity profiles for the higher molecular weight PS-b-PMMA $\left(33-b-33 \mathrm{~kg} \mathrm{~mol}^{-1}\right)$ system are shown in Figure 3. Horizontal line cuts along $\mathrm{q}_{\mathrm{x}}$ (in the $\mathrm{X}-\mathrm{Y}$ plane of the scattering geometry) and vertical line cuts along $\mathrm{q}_{\mathrm{z}}$ as indicated by the boxed areas in Figure 3.a allow quantification for in-plane (perpendicular lamellae) and out-of-plane (parallel lamellae) ordering, respectively, as shown in Figure 3.e-f. 

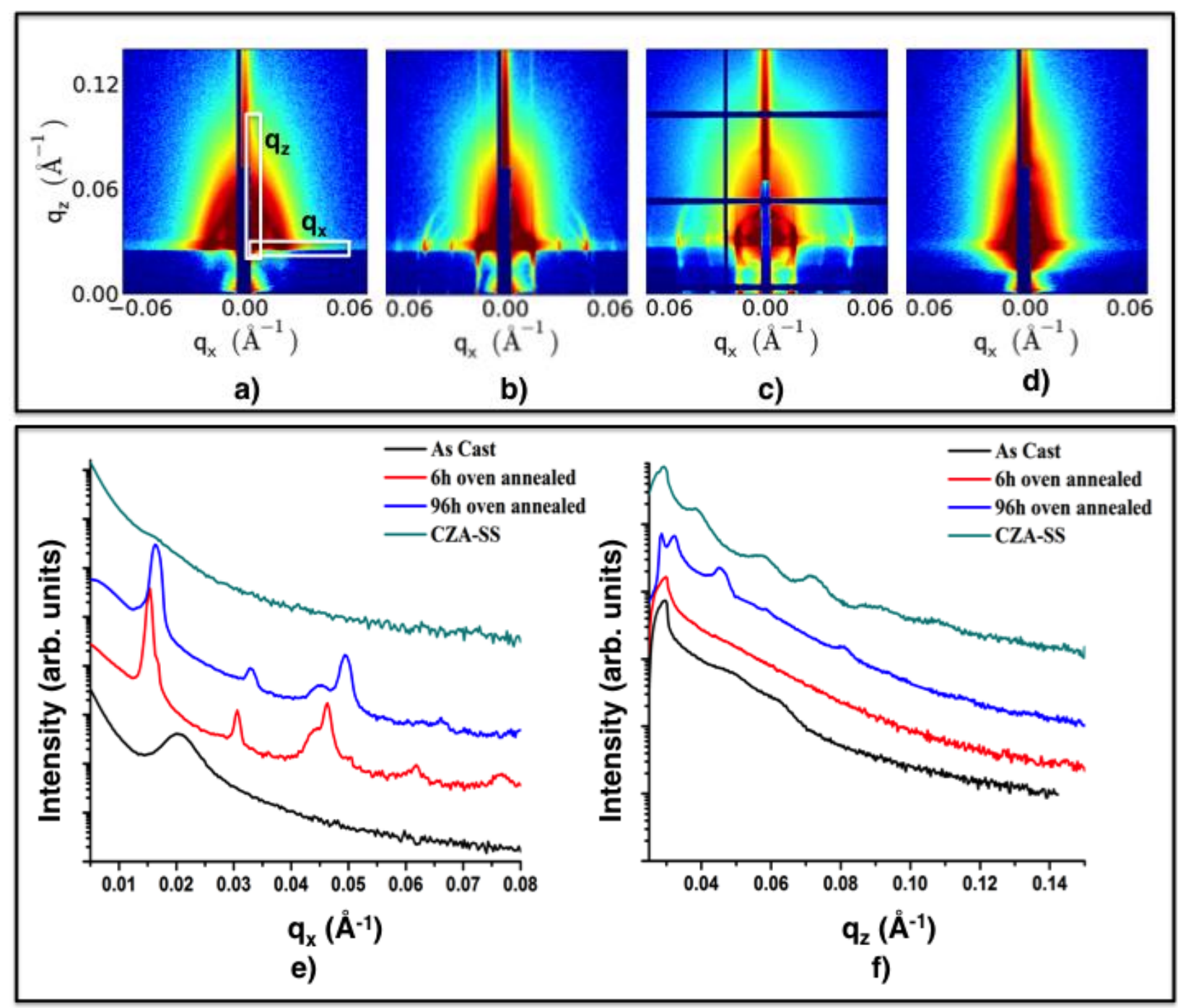

Figure 3. Probing the ordering and orientation of BCP films using GISAXS. 2-dimensional

GISAXS images of a) as-cast, b) short time oven-annealed (6 h), c) long time oven annealed (96 h) and d) CZA-SS processed films with corresponding e) in-plane and f) out-of-plane integrated intensity profiles for PS- $b$-PMMA (33- $\left.b-33 \mathrm{~kg} \mathrm{~mol}^{-1}\right)$.

The as-cast film exhibits a very broad first order peak in $\mathrm{q}_{\mathrm{x}}$ and no distinct peaks in $\mathrm{q}_{\mathrm{z}}$, which is typical for poorly ordered materials lacking well-defined domains (Figure 3.a), whereas oven annealing results in the appearance of peaks along both $\mathrm{q}_{\mathrm{x}}$ and $\mathrm{q}_{\mathrm{z}}$, indicating the coexistence of perpendicular and parallel lamellar orientation (Figure 3.b, c). For the $6 \mathrm{~h}$ oven-annealed 
sample, up to 4 orders of in-plane Bragg peaks with $\mathrm{q}_{\mathrm{x}}$ values in the ratio 1:2:3:4 are observed, while none out-of-plane $\left(\mathrm{q}_{\mathrm{z}}\right)$, indicative of predominantly perpendicular lamellae throughout the film. At longer annealing times $(96 \mathrm{~h})$, there is an appearance of higher-order out-of-plane $\left(\mathrm{q}_{\mathrm{z}}\right)$ peaks along with the in-plane $\left(\mathrm{q}_{\mathrm{x}}\right)$ peaks indicating a mixed lamellar morphology. The diffuse isotropic rings connecting the in-plane and out-of-plane Bragg peaks is a signature of lamellae with mixed orientations. Thus, with increasing annealing time, parallel oriented BCP domains are favored over vertical orientation, as discussed previously. Nevertheless, there exists a point where the morphology does not evolve further with additional annealing. In contrast to oven annealing, CZA-SS processed films exhibit no distinct peaks along $\mathrm{q}_{\mathrm{x}}$ indicating there is no perpendicular lamellae component, while higher-order peaks are observed along $\mathrm{q}_{\mathrm{z}}$ indicating a morphology with well-defined lamellar domains oriented parallel to the substrate. The presence of a faint bump in the CZA-SS intensity curve (green), around the position of first maxima of the oven-annealed curves in Figure 3.e, can be attributed to a slight in-plane modulation in the parallel lamellar structure; however, considering the intensity and the breadth of the bump in comparison with the Bragg peaks of oven annealed curves, it can be concluded that there is no significant vertical component and that the parallel ordering is near perfect. Similar GISAXS trends are observed for the low molecular weight PS- $b$-PMMA (19.5-b-18.1 $\mathrm{kg} \mathrm{mol}^{-1}$ ) films (see Supporting Information Figure $\mathrm{S} 2$ ); in fact the $\mathrm{q}_{\mathrm{x}}$ integrated intensity line-cut for the CZA-SS sample show no sign of in-plane modulations indicating a perfect parallel lamellar structure.

The processing-morphology trend for the PS- $b$-P2VP films is very similar to that for PS- $b$ PMMA as evidenced by the cross-sectional TEM images and complementary GISAXS data shown in Figure 4. The TEM of as-cast films resembles a homogenous single-phase system, while GISAXS shows very broad spots in $\mathrm{q}_{\mathrm{x}}$ indicating domains lacking any long-range order. 
Short time oven annealing results in morphology with mixed lamellar orientations having a predominant perpendicular component. The CZA-SS processed films show extremely well ordered and highly oriented parallel lamellae (domain size $\sim 37 \mathrm{~nm}$ ) that resemble a multilayered structure of alternating PS and P2VP layers. These results clearly underscore the importance of the CZA-SS process and its general applicability to continuously fabricate highly oriented, wellordered lamellar structures in micron thick BCP films on non-modified, conductive substrates at much faster rates than conventional annealing and potentially over large areas. For BCPs, the domain size $\mathrm{L}_{0}$ or the lamellar thickness is a function of the molecular weight $(\mathrm{N}$ : degree of polymerization) and the interaction parameter between the two blocks $(\chi) ; \mathrm{L}_{0} \alpha \chi^{1 / 6} \mathrm{~N}^{2 / 3} \cdot{ }^{38} \mathrm{In}$ this work, we used two different molecular weights of PS- $b$-PMMA, thereby increasing the domain size from $27 \mathrm{~nm}$ to $37.5 \mathrm{~nm}$ and decreasing corresponding number of lamellar layers from $\sim 88$ to $\sim 63$ for PS- $b$-PMMA (19.5-b-18.1 $\mathrm{kg} \mathrm{mol}^{-1}$ ) and PS- $b$-PMMA (33-b-33 $\mathrm{kg} \mathrm{mol}^{-1}$ ) respectively, while keeping film thickness constant around $1 \mu \mathrm{m}$. Recent trends in BCP lithography have pushed the lower limits of lamellar thicknesses achievable down to $\sim 5 \mathrm{~nm} .{ }^{39}$ Thus, by changing the block chemistry $(\chi)$, molecular weight or even film thickness, the lamellar thicknesses and corresponding number of layers can be readily tuned. Since, CZA-SS operates via a shear mechanism, it has broad applicability over a range of chemistries, molecular weights and film thicknesses to achieve highly ordered self-asembled BCDFs, as long as the shear stress is sufficient to direct the self-assembly. 


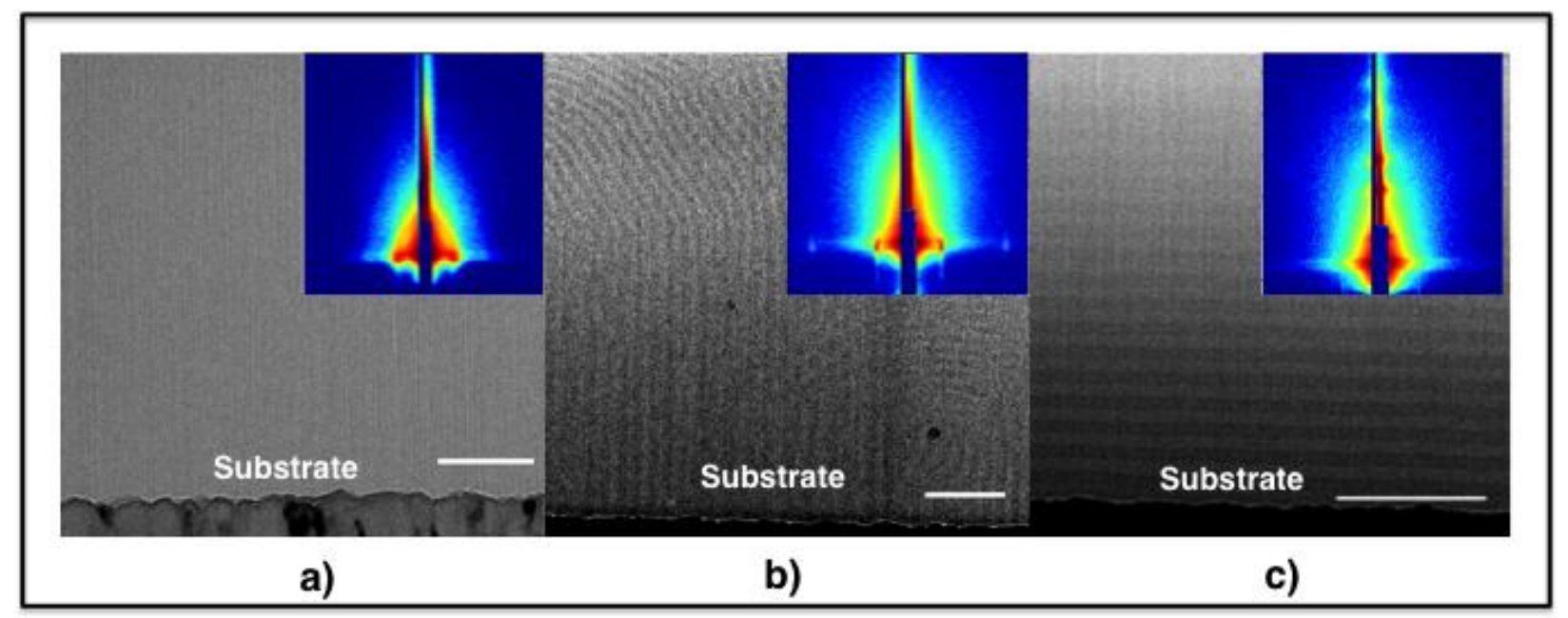

Figure 4. Morphology of PS-b-P2VP BCP films under different processing conditions. Cross-sectional TEM (no stain) images of a) as-cast, b) short time oven-annealed (6 h) and c) CZA-SS processed films of PS- $b$-P2VP $\left(25-b-25 \mathrm{~kg} \mathrm{~mol}^{-1}\right)$ on Al-coated quartz. Insets: 2dimensional GISAXS images of films corresponding to each sample. (Scale bar: $0.2 \mu \mathrm{m}$ )

Dielectric Performance of BCP Films: BCP films with representative unordered, perpendicular and parallel lamellar ordering were subjected to dielectric breakdown experiments to characterize dielectric strength. These were obtained by testing the film as-cast, annealing the film for $6 \mathrm{~h}$ under vacuum, and applying the CZA-SS procedure, respectively. Films annealed for $96 \mathrm{~h}$ that exhibit a mixture of lamellar orientations were also examined. Figure 5.a-d summarizes the dielectric failure data for PS (100 kg mol$\left.{ }^{-1}\right)$, P2VP (77 kg mol$\left.{ }^{-1}\right)$, PMMA (88 $\left.\mathrm{kg} \mathrm{mol}^{-1}\right)$ homopolymer control films, $33-b-33 \mathrm{~kg} \mathrm{~mol}^{-1}$ PS- $b$-PMMA, 19.5-b-18.1 $\mathrm{kg} \mathrm{mol}^{-1}{ }^{1}$ PS- $b$-PMMA and $25-b-25 \mathrm{~kg} \mathrm{~mol}^{-1} \mathrm{PS}-b-\mathrm{P} 2 \mathrm{VP}$ films respectively. 

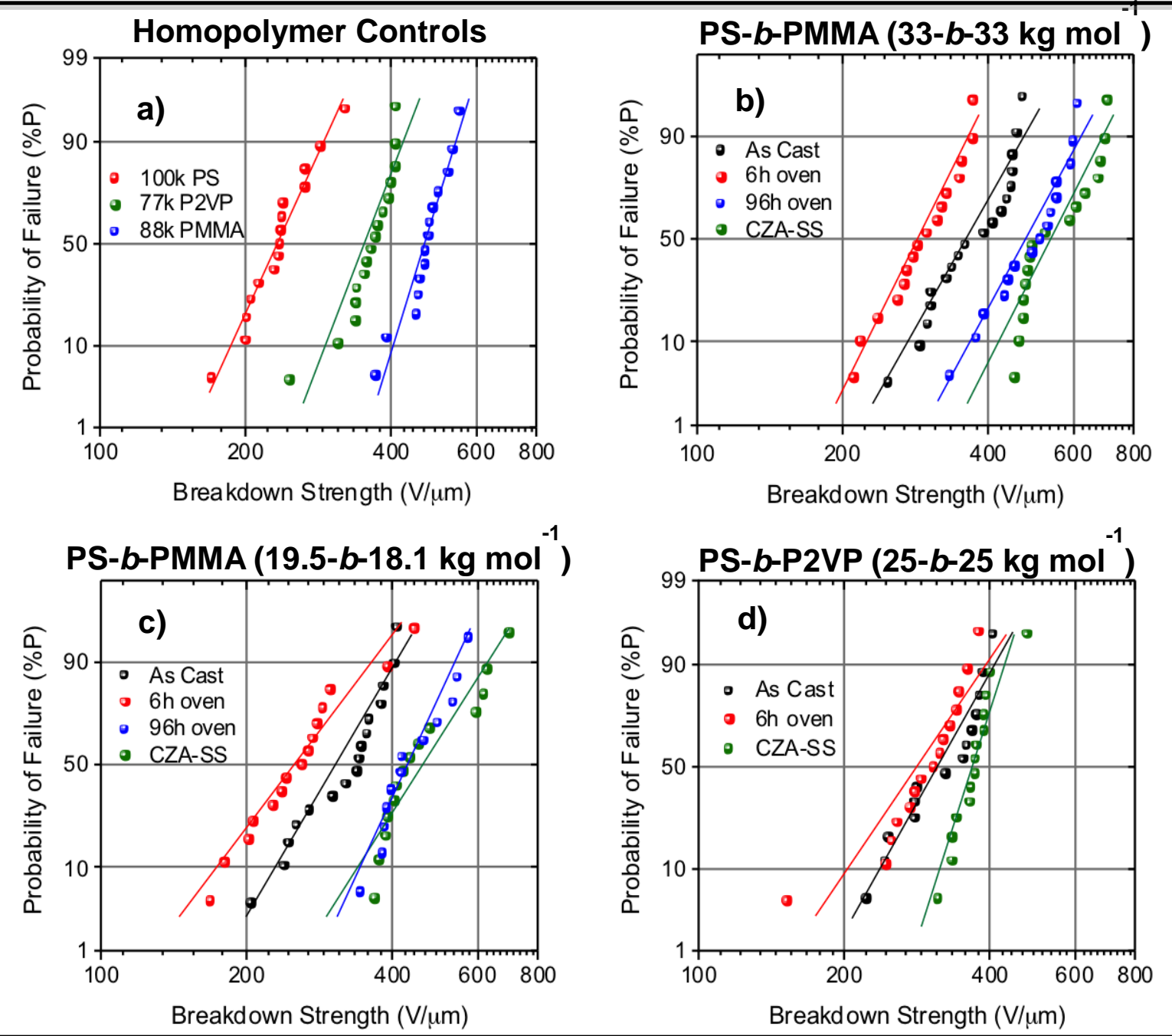

Figure 5. Dielectric breakdown properties of homopolymer and BCP dielectric films (BCDFs). Probability of failure for PS, PMMA, P2VP, PS- $b$-PMMA and PS- $b$-P2VP films: a) $100 \mathrm{~kg} \mathrm{~mol}^{-1} \mathrm{PS}$ (red), $77 \mathrm{~kg} \mathrm{~mol}^{-1} \mathrm{P} 2 \mathrm{VP}$ (green) and $88 \mathrm{~kg} \mathrm{~mol}^{-1}$ PMMA (blue), b) 33-b-33 kg $\mathrm{mol}^{-1}$ PS- $b$-PMMA films c) $19.5-b-18.1 \mathrm{~kg} \mathrm{~mol}^{-1}$ PS- $b$-PMMA films and d) $25-b-25 \mathrm{~kg} \mathrm{~mol}^{-1}$ PS- $b$-P2VP films. Straight lines correspond to two-parameter Weibull fittings.

A two-parameter Weibull cumulative probability function was employed to fit the data and is given by $P(E)=1-\exp \left[-\left(E / E_{B D}\right)^{\beta}\right]$, where $P(E)$ is the cumulative probability for failure, $E$ is experimental breakdown strength, $E_{\mathrm{BD}}$ reflects the electric field where there is $63.2 \%$ probability 
for failure, $\beta$ is the shape parameter associated with the least squares fit of the distribution. Data from these fits are summarized in Table 1. The PS and PMMA homopolymer films yielded $E_{\mathrm{BD}}$ values of $251 \mathrm{~V} / \mu \mathrm{m}$ and $494 \mathrm{~V} / \mu \mathrm{m}$, respectively (Figure 5.a). Thus, a film comprised of 1:1 PS: PMMA would be expected to have characteristic breakdown strength of $\sim 375 \mathrm{~V} / \mu \mathrm{m}$ by simple rule-of-mixtures. As-cast $33-b-33 \mathrm{~kg} \mathrm{~mol}^{-1}$ PS- $b$-PMMA films yielded a breakdown strength value of $403 \mathrm{~V} / \mu \mathrm{m}$, which is comparable to this rule-of-mixture estimate (Figure 5.b). Films annealed for $6 \mathrm{~h}$ exhibited a significant drop off in breakdown strength $(316 \mathrm{~V} / \mu \mathrm{m})$, while films annealed for $96 \mathrm{~h}$ showed an enhancement $(529 \mathrm{~V} / \mu \mathrm{m})$ as compared to the as-cast film. CZA-SS processed films exhibited the best performance with an $E_{\mathrm{BD}}$ value of $599 \mathrm{~V} / \mu \mathrm{m}$, which is a $60 \%$ improvement above the rule-of-mixtures estimation. Similar trends were observed for the lower molecular weight PS- $b$-PMMA $\left(19.5-b-18.1 \mathrm{~kg} \mathrm{~mol}^{-1}\right)$, with $E_{\mathrm{BD}}$ values approximately $10 \%$ lower when comparing equivalent sample morphologies. Here, the as-cast film yielded an $\mathrm{E}_{\mathrm{BD}}$ value of $346 \mathrm{~V} / \mu \mathrm{m}$, while the $6 \mathrm{~h}$ and $96 \mathrm{~h}$ films had breakdown strengths of $286 \mathrm{~V} / \mu \mathrm{m}$ and 476 $\mathrm{V} / \mu \mathrm{m}$, respectively. The CZA-SS sample again exhibited the highest breakdown strength with a value of $520 \mathrm{~V} / \mu \mathrm{m} . \beta$ values were observed to be unaffected by molecular weight or morphology for PS-b-PMMA films, falling in the range of 4-7 for all films under investigation. Results for breakdown tests performed on $25-b-25 \mathrm{~kg} \mathrm{~mol}^{-1} \mathrm{PS}-b$-P2VP films (as-cast, annealed for $6 \mathrm{~h}$, and CZA-SS processed) are shown in Figure 5.d. Here, the breakdown strength trend matches the one observed for the PS- $b$-PMMA, which proves the general dependence of the breakdown on the nanostructure of the $\mathrm{BCP}$ films irrespective of the disparity in dielectric properties of

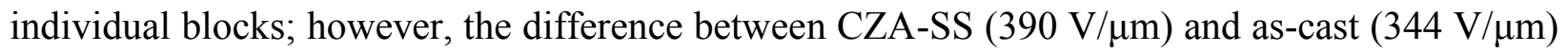
films was smaller ( $\sim 14 \%$ enhancement) as compared to the PS- $b$-PMMA samples. It is interesting to note that although the morphology and layer thickness for both CZA-SS processed 
$25-b-25 \mathrm{~kg} \mathrm{~mol}^{-1} \mathrm{PS}-b-\mathrm{P} 2 \mathrm{VP}$ and $33-b-33 \mathrm{~kg} \mathrm{~mol}^{-1} \mathrm{PS}-b-\mathrm{PMMA}$ films is similar ( $\left.\sim 37 \mathrm{~nm}\right)$, there is disparity in the breakdown strength enhancement. This can be attributed to the breakdown

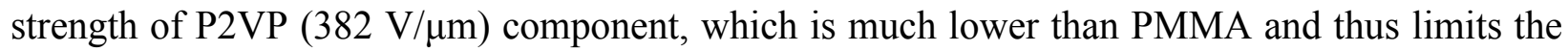
breakdown strength enhancement available to PS- $b$-P2VP as compared with PS- $b$-PMMA.

Table 1. Summary of characteristic dielectric breakdown strength $\left(E_{\mathrm{BD}}\right)$ and shape parameter $\beta$ measured for PS, PMMA, PS- $b$-PMMA and PS-b-P2VP films.

\begin{tabular}{|c|c|c|c|}
\hline \multicolumn{2}{|c|}{ Sample } & $\boldsymbol{E}_{\text {BD }}(\mathrm{V} / \mu \mathrm{m})$ & $\beta$ \\
\hline \multicolumn{2}{|c|}{ 100k PS } & 251 & 7.1 \\
\hline \multicolumn{2}{|c|}{ 77k P2VP } & 382 & 8.5 \\
\hline \multicolumn{2}{|c|}{ 88k РММА } & 494 & 10.2 \\
\hline \multirow{4}{*}{$\begin{array}{l}\text { 19.5k-b-18.1k } \\
\text { PS-b-PMMA }\end{array}$} & $6 \mathrm{~h}$ oven & 289 & 4.1 \\
\hline & As-cast & 346 & 5.4 \\
\hline & $96 \mathrm{~h}$ oven & 467 & 6.4 \\
\hline & CZA-SS & 520 & 4.6 \\
\hline \multirow{4}{*}{$\begin{array}{c}\text { 33k-b-33k } \\
\text { PS-b-PMMA }\end{array}$} & $6 \mathrm{~h}$ oven & 316 & 6.4 \\
\hline & As-cast & 403 & 5.8 \\
\hline & $96 \mathrm{~h}$ oven & 529 & 6.2 \\
\hline & CZA-SS & 599 & 6.1 \\
\hline \multirow{3}{*}{$\begin{array}{l}25 k-b-25 k \\
\text { PS-b-P2VP }\end{array}$} & $6 \mathrm{~h}$ oven & 322 & 4.9 \\
\hline & As-cast & 344 & 5.4 \\
\hline & CZA-SS & 390 & 10.4 \\
\hline
\end{tabular}


Focusing on the high-breakdown strength PS- $b$-PMMA system, we discuss the results in more detail, outlining the likely mechanism of $E_{\mathrm{BD}}$ enhancement. The results of Figure 5 clearly demonstrate how BCP morphology impacts breakdown strength, as we observe significant differences in $E_{\mathrm{BD}}$ for $6 \mathrm{~h}$ oven annealed PS- $b$-PMMA samples when compared to CZA-SS processed films. The compositions of the films are identical - only their sample morphologies are changed (perpendicular lamellae vs parallel lamellae). The dielectric strength for both molecular weight as-cast PS- $b$-PMMA films falls within $10 \%$ of the rule-of mixtures breakdown estimate. This supports the idea that as-cast films behave similarly to a single-phase polymer system whose dielectric behavior is an average of its constituents. Forcing lamellae to align predominantly perpendicular within the film - as in the $6 \mathrm{~h}$ annealed films - yielded breakdown values closer to neat PS $(250 \mathrm{~V} / \mu \mathrm{m})$. Since failure is more likely to occur in the poorer breakdown component (PS) and the perpendicular lamellae can span much of the entire sample thickness, it is likely both breakdown initiation and propagation events take place within PS blocks only. In contrast, the films with parallel lamellae obtained via CZA-SS gave $E_{\mathrm{BD}}$ values $50 \%$ higher than their as-cast counterparts. Interestingly, these values were even higher than the stronger component PMMA ( $494 \mathrm{~V} / \mu \mathrm{m})$ of the film, with $\sim 5 \%$ increase for the lower molecular weight and $\sim 21 \%$ increase for the higher molecular weight PS- $b$-PMMA over pure PMMA control film. This clearly indicates an enhancement due to morphology and is significant considering the energy density scales as the square of the $E_{B D}$. We attribute this to the introduction of multiple interfaces within the layered film, which act as barriers to the applied electric field, providing a tortuous pathway for the electrical tree propagation thereby forestalling the breakdown process. 
Experimental and simulation studies of the barrier effect on breakdown of polymers, suggest that the inherent differences in permittivity or conductivity between matrix and barrier components lead to formation of space charges at the interfaces that act opposite to the applied field and cause the resulting electrical tree to propagate tangentially to the interface i.e. along the barrier rather than along the film surface normal. ${ }^{13-17}$ Evidence of interfacial propagation of trees due to barrier effect was observed by Vogelsang et.al in epoxy systems with mica barriers. ${ }^{17}$ Wolak et.al observed breakdown damage and layer delamination a few microns away from the position of the top electrode in the cross-sections of co-extruded multilayered films; effects not observed in single component films, thus suggesting interfacial phenomena. ${ }^{40}$ Drawing comparisons to our BCP system with highly uniform multilayered nanostructure, we believe that the interfaces between the two blocks act as barriers to electrical tree propagation. In theories of the breakdown process in polymers, it is postulated that electrical tree formation entails dissociation of bonds and degradation of the polymer leading to formation of conducting channels. ${ }^{11-12}$ We hypothesize that for the electrical tree to penetrate across the multilayered BCP film, it must overcome the block interfacial barriers and in order to do so, it must break bonds at the interface. In previous studies of the barrier effect, it has been shown that the tree propagation is highly sensitive to the interfacial strength i.e. the type of bonding between the barrier and the matrix. ${ }^{41}$ In the case of the highly ordered and aligned BCP, the barrier interfaces are sharp and constituted by strong covalent bonds between the two blocks. Hence, we believe the $E_{\mathrm{BD}}$ values are highest for CZA-SS processed parallel lamellar films where the multiple sharp interfaces of the lamellae with strong covalent bonds are highly oriented throughout the film, normal to direction of tree propagation, in contrast to 6 hour oven annealed films where the interfaces are parallel to the direction of tree propogation. The high lateral coherence of the 
parallel lamellae must force the tree along a tortuous pathway along the interfaces until, at a higher field strength (enhanced $E_{B D}$ ) it overcomes the barrier to propagate towards the other electrode, causing breakdown. Higher molecular weight PS-b-PMMA films $\left(33-b-33 \mathrm{~kg} \mathrm{~mol}^{-1}\right)$ exhibited consistently higher breakdown strengths for all sample morphologies, which is consistent with previous experiments performed on semicrystalline and amorphous homopolymers. For instance, the dielectric strength of polystyrene has been shown to monotonically increase with increasing molecular weight, where the largest changes occur around $20 \mathrm{~kg} / \mathrm{mol}$ - close to the entanglement molecular weight $(16 \mathrm{~kg} / \mathrm{mol}) .{ }^{42} \mathrm{~A} 10 \%$ difference in $E_{B D}$ was reported when comparing polystyrene films of molecular weight 19 and $33 \mathrm{~kg} / \mathrm{mol}$. Combined with similar differences expected for PMMA breakdown strength, we can explain the discrepancies between the lower and higher molecular weight BCP films. This behavior may be caused by differences in regularity of molecular conformation or density of chain ends within the film.

The improvement in breakdown strength facilitated by the layered film architecture comes at no cost to the relative permittivity and loss of the films. The permittivities of BCP films essentially follow a mean-field approximation and the values lie between those of component homopolymers. Dielectric spectroscopy experiments demonstrate that all PS- $b$-PMMA and PS- $b$ P2VP samples, regardless of morphology and molecular weight, have comparable permittivity spectra as shown in Figure 6.a-b and Supporting Information Figure S4. This is expected as the relative composition of the PS and PMMA/P2VP block fraction remains constant for all samples; only the morphology is variant. Therefore, we have successfully improved breakdown strength with no deleterious effect to the relative permittivity or loss ( $\tan \delta)$, which is of critical importance when considering the energy storage performance of the films. 


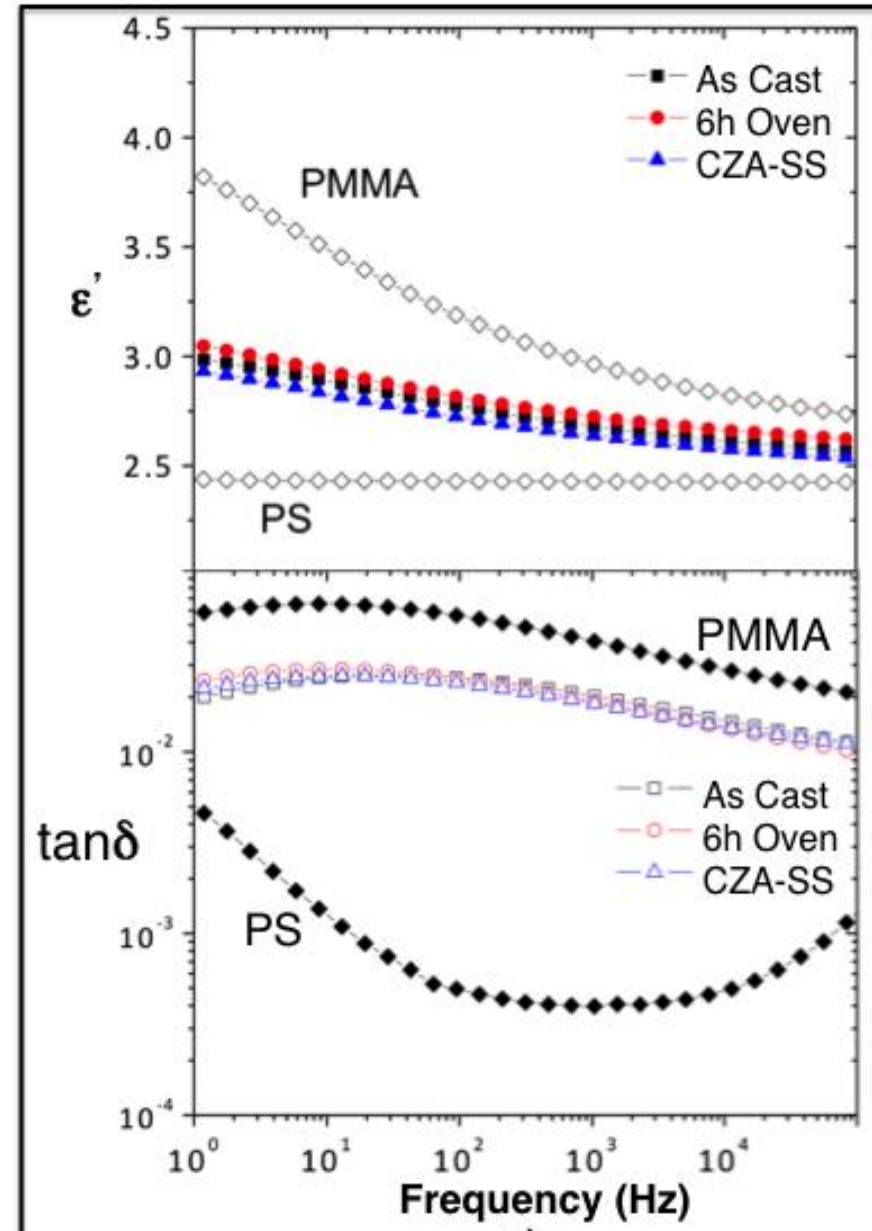

a)

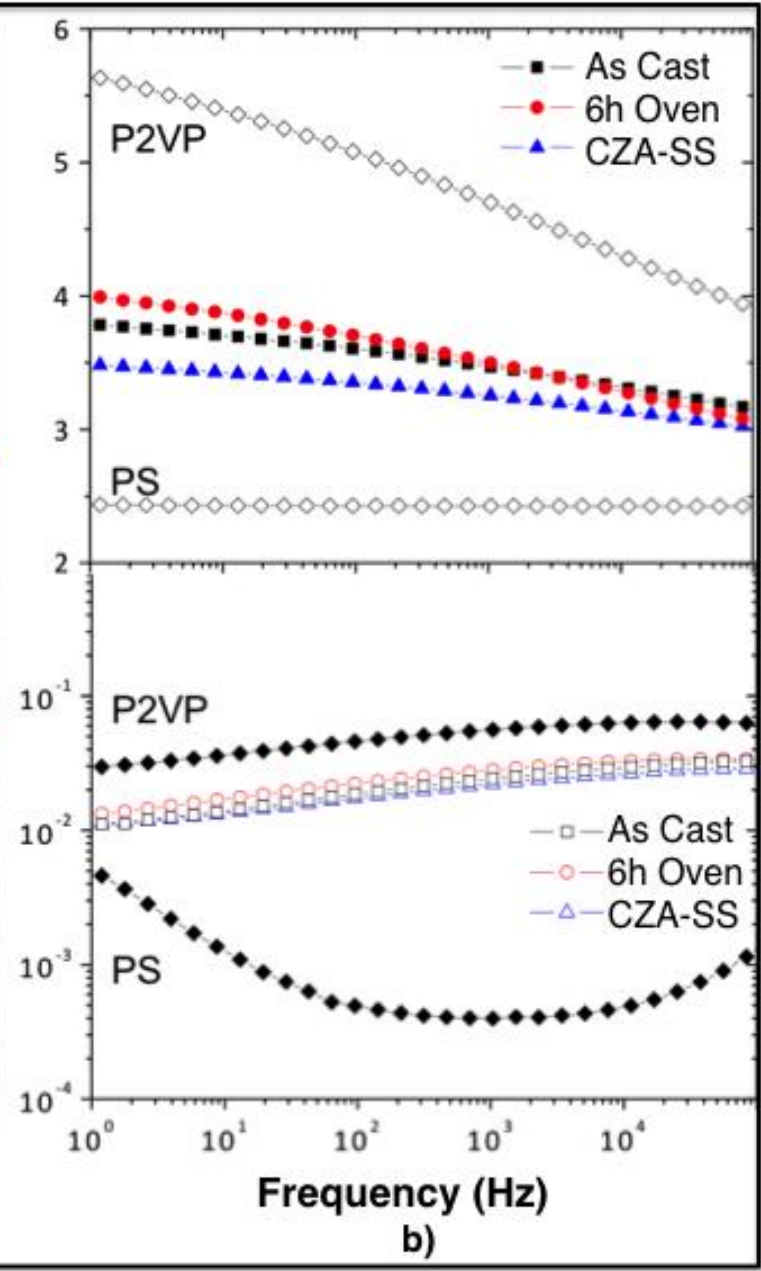

b)

Figure 6. Dielectric spectroscopy of homopolymer and BCP dielectric films (BCDFs).

Dielectric permittivity ( $\varepsilon^{\prime}$, top) and loss tangent ( $\tan \delta$, bottom) of homopolymer controls and BCP films with different orientations measured at discrete frequencies in the range of $1 \mathrm{~Hz}$ to 1 MHz at $1 \mathrm{~V}_{\mathrm{AC}}$ amplitude for a) $19.5-b-18.1 \mathrm{~kg} \mathrm{~mol}^{-1}$ PS- $b$-PMMA and b) $25-b-25 \mathrm{~kg} \mathrm{~mol}^{-1}$ PS- $b$ P2VP.

The maximum theoretical energy storage densities of the BCDFs with different morphologies and respective homopolymer controls are calculated based on Equation 1 using the experimentally obtained $E_{\mathrm{BD}}$ and $\varepsilon_{\mathrm{r}}$ values. The energy density trends are plotted in Figure 7 . The 
CZA-SS processed films with parallel lamellae always exhibit higher energy densities than corresponding as-cast or oven annealed films for both PS- $b$-PMMA and PS- $b$-P2VP. Infact, the PS- $b$-PMMA films with layered architecture exhibit more than double ( $\sim 2.25$ times) the energy storage density $\left(4.6 \mathrm{~J} / \mathrm{cm}^{3}\right)$ as compared to the as-cast films $\left(2 \mathrm{~J} / \mathrm{cm}^{3}\right)$ and $\sim 3.5$ times that of oven annealed films $\left(1.3 \mathrm{~J} / \mathrm{cm}^{3}\right)$ with predominantly perpendicular lamellae. They also exhibit higher energy storage performance than the individual PS and PMMA homopolymer components. It is noteworthy that although the $\mathrm{BCP}$ systems used here comprise of amorphous polymer components rather than semicrystalline polymer capacitor materials, yet the maximum energy densities obtained using the self-assembly approach are comparable or even higher $\left(4.6 \mathrm{~J} / \mathrm{cm}^{3}\right)$ than the industrial-standard semicrytalline BOPP films $\left(4 \mathrm{~J} / \mathrm{cm}^{3}\right)$. With a judicious choice of BCP comprising a high dielectric strength $\left(E_{\mathrm{BD}}\right)$ block, say semicrystalline $\mathrm{PP}$, and another block with high permittivity $\left(\varepsilon_{\mathrm{r}}\right)$, say PVDF, the resulting energy storage density (a product of the two quantities) could be significantly enhanced through this self-assembly strategy in future applications of this technology. Thus the BCP strategy allows for the design of block specific functionality and is not only significant from the energy storage point of view, but the weaker dielectric component may be used to incorporate other useful properties such as high mechanical strength, UV resistance, high refractive index, low oxygen permeability, which permit use of these films in other multifunctional technologies. For instance, in the present system, one may consider that in the case of higher molecular weight PS- $b$-PMMA, we enhanced the breakdown strength of the stronger component (here PMMA) by $\sim 21 \%$ which is notable, while the PS layers can bring auxillary function such as better UV resistance for outdoor applications. 


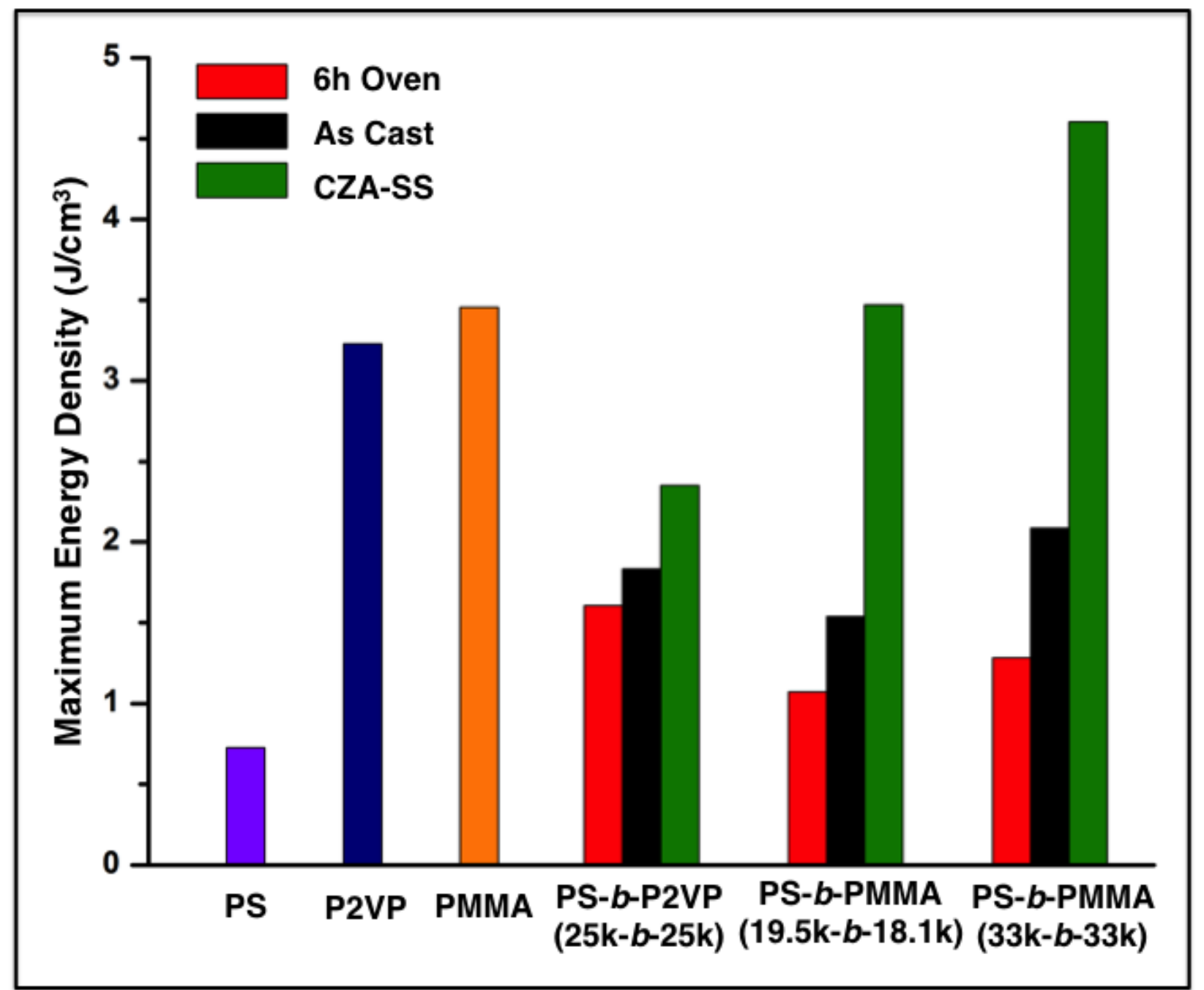

Figure 7. Energy density trends of homopolymer films and BCP dielectric films (BCDFs).

Maximum theoretical energy storage performance of component homopolymer and $\mathrm{BCP}$ dielectric films under different processing conditions, calculated from Equation (1) using experimentally obtained values of breakdown strength $\left(E_{\mathrm{BD}}\right)$ and relative permittivity $\left(\varepsilon_{\mathrm{r}}\right)$.

\section{Conclusion}

We have successfully demonstrated a new material design and processing method to fabricate block copolymer dielectric film (BCDF) capacitors with multilayered (lamellar) nanostructured dielectric media via directed self-assembly. CZA-SS is a powerful technique to fabricate highly 
orderd $\mathrm{BCP}$ on non-modified conductive (rigid or flexible) substrates and is also viable with high-throughput roll-to-roll processing as compared to other directed self-assembly methods. The highly ordered lamellar structures obtained by CZA-SS yield up to $\sim 50 \%$ increase in $E_{\mathrm{BD}}$ of the nanostructured $\mathrm{BCP}$ film when compared to an as-cast $\mathrm{BCP}$ film, due to the barrier effect. This translates to a $\sim 2.25$ times increase in the maximum energy storage density since it has a quadratic dependence on the $E_{\mathrm{BD}}\left(U=\frac{1}{2} \varepsilon_{0} \varepsilon_{r} E_{B D}{ }^{2}\right)$. With the potential to synthesize new BCPs having optimum dielectric properties, it is possible to obtain a catalog of tailored BCP materials. Using the simple but robust self-assembly strategy, these BCP materials can be used to fabricate multilayered high-energy density, pulsed power, flexible capacitor films for use in directed energy, electric vehicles and future high-power flexible electronics.

\section{Methods}

Film preparation: Diblock copolymers PS- $b$-PMMA $\left(M_{n}=66 \mathrm{~kg} \mathrm{~mol}^{-1}\right)$, deuterated PS- $b$ PMMA $\left(M_{n}=37.6 \mathrm{~kg} \mathrm{~mol}^{-1}\right)$ with the PS block deuterated, PS- $b$-P2VP $\left(M_{n}=50 \mathrm{~kg} \mathrm{~mol}^{-1}\right)$ and homopolymers PS (100 kg mol$\left.{ }^{-1}\right)$, PMMA $\left(88 \mathrm{~kg} \mathrm{~mol}^{-1}\right)$ and P2VP $\left(77 \mathrm{~kg} \mathrm{~mol}^{-1}\right)$ were purchased from PolymerSource Inc. and used as received. Electron beam physical vapor deposition was utilized to coat $100 \mathrm{~nm}$ thick aluminum films (roughness $\sim 2 \mathrm{~nm}$ ) onto quartz slides (GM Associates Inc.) to form the bottom electrode for breakdown testing. Polymer samples were dissolved in toluene and $10 \%(\mathrm{w} / \mathrm{w})$ solutions were flow-coated (Supplementary Figure 1) onto UV-Ozone (Novoscan Tech., Inc) cleaned Al-coated (1 inch $\times 3$ inch) quartz slides. UV-Ozone treatment removes organic impurities from the substrate surface, forms an oxide layer and thereby increases wettability of polymer film. Film thicknesses were measured 
using a Bruker DektakXT profilometer. Prior to processing, the films were dried in a vacuum oven at $65^{\circ} \mathrm{C}$ for 12 hours to remove residual solvent.

Preparation and installation of PDMS pad: Sylgard-182 (Dow Corning Corp., USA) was used to make the polydimethylsiloxane (PDMS) films. The PDMS elastomer/curing agent (20:1 weight ratio) were mixed and de-aerated in vacuum followed by pouring onto a glass microscope slide. The mixture was then cured at $120{ }^{\circ} \mathrm{C}$ for $6 \mathrm{~h}$. PDMS was then peeled off the glass to obtain $\sim 0.5 \mathrm{~mm}$ thick smooth films. PDMS pad of dimensions similar to the film $(\sim 2.5 \mathrm{~cm}$ lateral size) was cut out and manually placed onto the BCP film by light pressing. The PDMS is prepared on a smooth glass surface, hence the smooth PDMS surface allows for conformal contact with the film during the CZA-SS process.

Film processing: The BCP sample with PDMS pad was then translated across the CZA-SS gradient assembly (Supporting Information) at a speed of $5 \mu \mathrm{m} / \mathrm{s}$ using a syringe pump. The CZA-SS procedure was performed under ambient conditions. After CZA-SS, the PDMS was manually peeled off the film after the film is cooled below $T_{g}$ of both blocks. Below $T_{g}$, the film is in the glassy state and adhered to the substrate, hence stable during the peeling process.

Conventional oven annealing was carried out in an oven at $205^{\circ} \mathrm{C}$ under vacuum.

Electron Microscopy: TEM samples of the film cross-sections were made via the in-situ lift-out method using a FEI Helios 600 dual-beam FIB and imaged with a JEOL 1400 LAB6 TEM at $120 \mathrm{keV}$. All images are brightfield images.

Neutron Reflectivity: The Neutron Reflectivity (NR) experiments were carried out on the NG7 horizontal reflectometer at NIST Center for Neutron Research. A $4.76 \AA ̊$ collimated neutron beam with a wavelength divergence of $0.18 \AA$ was used. Scans were made over a wave vector 
magnitude $\left(\mathrm{q}_{\mathrm{z}}\right)$ range from $0.005 \AA^{-1}$ to $0.16 \AA^{-1}$. A pure quartz substrate was used in place of Al-coated quartz for the NR measurements for ease of data fitting. Data fitting and conversion of the NR spectra to the scattering length density (SLD) and concentration profile was done using Reflpak software (NIST CNR).

Grazing-Incidence Small-Angle X-ray Scattering: GISAXS experiments were performed at beamline 8-ID of the Advanced Photon Source, Argonne National Laboratory, as well as beamline X9 of the National Synchrotron Light Source, Brookhaven National Laboratory. An Xray beam of $7.35 \mathrm{keV}$ (8-ID) or $14.1 \mathrm{keV}$ (X9) impinged on the films (in vacuum) at an angle well above the critical angle of the films, to probe bulk of the film. Data was collected on a Dectris Pilatus 1M pixel-array detector. Data analysis and conversion to q-space was done using GIXSGUI software in MatLab, developed at beamline 8-ID.

Dielectric Testing: All samples were annealed at $80{ }^{\circ} \mathrm{C}$ for $12 \mathrm{~h}$ prior to breakdown testing to remove residual solvent and adsorbed moisture that may be present within the film. Dielectric breakdown trials were performed using a $10 \mathrm{kV}$ Spellman SL300 high voltage supply controlled by a ramping circuit (Supporting Information Figure S3). The ramp was set such that a breakdown event occurs at $\sim 20$ seconds, in accordance to ASTM standard protocol for shortterm dielectric strength tests (which corresponds to 50-300 V/s, depending on the sample). ${ }^{43}$ Once $>1 \mathrm{~mA}$ current passes through the device, a silicon rectifier switch activates and breaks the circuit. The breakdown voltages were read from a Fluke 289 multimeter set in peak capture mode. Our experimental geometry features a copper rod with a hemispherical end (radius of curvature $=2.5 \mathrm{~mm}$ ) that makes direct contact with the $\mathrm{BCP}$ film. Breakdown is confined to a small sample region (area $\sim 0.1 \mathrm{~cm}^{2}$ ) in an attempt to remove the influence of film heterogeneity by spatially localizing the electric field. At least 15 breakdown trials were performed for each 
film to conduct Weibull failure analysis. The copper contact rod was polished after every 15 breakdowns using diamond paste to remove pitting. All experiments were conducted at room temperature in an $\mathrm{N}_{2}$ purged environment where relative humidity was observed in the range of $10-20 \%$. Breakdown voltages were converted to breakdown strength by measuring film thickness near each test site via profilometry.

Permittivity measurements were conducted using a Novocontrol Impedance Spectroscopy Analyzer and facilitated by coating the BCP films with a $3 \mathrm{~mm}$ diameter circular aluminum top electrode.

Supporting Information Available. Schematic of the flow coating method, CZA-SS experimental procedure, GISAXS data of PS- $b$-PMMA (19.5-b-18.1 $\mathrm{kg} \mathrm{mol}^{-1}$ ) films, schematic of dielectric breakdown test set-up and dielectric spectroscopy of PS-b-PMMA (33-b-33 kg mol${ }^{-}$ $\left.{ }^{1}\right)$ films. This material is available free of charge via the Internet at http://pubs.acs.org.

\section{ACKNOWLEDGMENT}

This work was supported by AFOSR under contract No. FA9550-12-1-0306. CZA-SS work was supported by the National Science Foundation (NSF) via Grant DMR-1006421. Research carried out at the Center for Functional Nanomaterials, and the National Synchrotron Light Source, Brookhaven National Laboratory, is supported by the U.S. Department of Energy, Office of Basic Energy Sciences, under Contract No. DE-SC0012704. Research carried out at the Advanced Photon Source, is supported by the U.S. Department of Energy (DOE) Office of Science User, under Contract No. DE-AC02-06CH11357. The authors would like to thank Joseph Strzalka for help with the GISAXS measurements at beamline 8-ID, Advanced Photon 
Source, Argonne National Laboratory. S.P.S. and A.K. would also like to thank Gurpreet Singh, Danielle Grolman, Sarang Bhaway and Arvind Modi for fruitful discussions.

\section{Corresponding Author}

*Alamgir Karim * (alamgir@uakron.edu $)$

\section{Author Contributions}

The manuscript was written through contributions of all authors. All authors have given approval to the final version of the manuscript.

\section{Funding Sources}

This work was supported by Air Force Office of Scientific Research (AFOSR) under contract No. FA9550-12-1-0306 and the National Science Foundation (NSF) via Grant DMR-1006421.

\section{Notes}

Competing financial interests: The authors declare no competing financial interests.

Disclaimer: Certain commercial equipment, instruments, or materials (or suppliers, or software, etc.) are identified in this paper to foster understanding. Such identification does not imply recommendation or endorsement by the National Institute of Standards and Technology, nor does it imply that the materials or equipment identified are necessarily the best available for the purpose. 


\section{REFERENCES}

(1) Wang, Q.; Zhu, L. Polymer Nanocomposites for Electrical Energy Storage. J. Polym. Sci. Part B Polym. Phys. 2011, 49 (20), 1421-1429.

(2) Wolak, M. A.; Pan, M.J.; Wan, A.; Shirk, J. S.; Mackey, M.; Hiltner, A.; Baer, E.; Flandin, L. Dielectric Response of Structured Multilayered Polymer Films Fabricated by Forced Assembly. Appl. Phys. Lett. 2008, 92 (11), 1133011-1133013.

(3) Reed, C. W.; Cichanowski, S. W. Fundamentals Of Aging in HV Polymer-Film Capacitors. IEEE Trans. Dielectr. Electr. Insul. 1994, 1 (5), 904-922.

(4) Wang, Y.; Zhou, X.; Chen, Q.; Chu, B.; Zhang, Q. Recent Development of High Energy Density Polymers for Dielectric Capacitors. IEEE Trans. Dielectr. Electr. Insul. 2010, 17, $1036-1042$.

(5) Sarjeant, W. J.; Zirnheld, J.; MacDougall, F. W. Capacitors. IEEE Trans. Plasma Sci. 1998, $26(5), 1368-1392$.

(6) Tchoul, M. N.; Fillery, S. P.; Koerner, H.; Drummy, L. F.; Oyerokun, F. T.; Mirau, P. A.; Durstock, M. F.; Vaia, R. A. Assemblies of Titanium Dioxide-Polystyrene Hybrid Nanoparticles for Dielectric Applications. Chem. Mater. 2010, 22 (5), 1749-1759.

(7) Kim, P.; Doss, N. M.; Tillotson, J. P.; Hotchkiss, P. J.; Pan, M.J.; Marder, S. R.; Li, J.; Calame, J. P.; Perry, J. W. High Energy Density Nanocomposites Based on SurfaceModified BaTiO3 and a Ferroelectric Polymer. ACS Nano 2009, 3 (9), 2581-2592.

(8) Jung, H. M.; Kang, J. H.; Yang, S. Y.; Won, J. C.; Kim, Y. S. Barium Titanate Nanoparticles with Diblock Copolymer Shielding Layers for High-Energy Density 
Nanocomposites. Chem. Mater. 2010, 22 (14), 450-456.

(9) Arbatti, M.; Shan, X.; Cheng, Z.-Y. Ceramic-Polymer Composites with High Dielectric Constant. Adv. Mater. 2007, 19, 1369-1372.

(10) Grabowski, C. A.; Koerner, H.; Meth, J. S.; Dang, A.; Hui, C. M.; Matyjaszewski, K.; Bockstaller, M. R.; Durstock, M. F.; Vaia, R. A. Performance of Dielectric Nanocomposites: Matrix-Free, Hairy Nanoparticle Assemblies and Amorphous PolymerNanoparticle Blends. ACS Appl. Mater. Interfaces 2014, 6 (23), 21500-21509.

(11) Ieda, M. Dielectric Breakdown Process of Polymers. IEEE Trans. Electr. Insul. 1980, EI15 (3), 206-224.

(12) Artbauer, J. Electric Strength of Polymers. J. Phys. D. Appl. Phys. 1999, 29, 446-456.

(13) Lebedev, S. M.; Gefle, O. S.; Polholkov, Y. P.; Chichikin, V. I. Two-Layer Dielectrics Behaviour in the Electric Field. Annu. Rep. Conf. Electr. Insul. Dielectr. Phenom. 1999, $265-268$.

(14) Gefle, O. S.; Lebedev, S. M.; Uschakov, V. Y. The Mechanism of the Barrier Effect in Solid Dielectrics. J. Phys. D: Appl. Phys. 1999, 30, 3267-3273.

(15) Agoris, D. P.; Vitellas, I.; Gefle, O. S.; Lebedev, S. M.; Pokholkov, Y. P. The Barrier Effect in Three-Layer Solid Dielectrics in Quasi-Uniform Electric Field. J. Phys. D. Appl. Phys. 2001, 34, 3485-3491.

(16) Farr, T.; Vogelsang, R.; Frohlich, K. A New Deterministic Model for Tree Growth in Polymers with Barriers. Annu. Rep. Conf. Electr. Insul. Dielectr. Phenom. 2001, 673-676. 
(17) Vogelsang, R.; Farr, T.; Fröhlich, K. The Effect of Barriers on Electrical Tree Propagation in Composite Insulation Materials. IEEE Trans. Dielectr. Electr. Insul. 2006, 13 (1), 373382.

(18) Mackey, M.; Hiltner, A.; Baer, E.; Flandin, L.; Wolak, M. A.; Shirk, J. S. Enhanced Breakdown Strength of Multilayered Films Fabricated by Forced Assembly Microlayer Coextrusion. J. Phys. D. Appl. Phys. 2009, 42 (17), 175304.

(19) Zhou, Z.; MacKey, M.; Carr, J.; Zhu, L.; Flandin, L.; Baer, E. Multilayered Polycarbonate/Poly(Vinylidene Fluoride-Co-Hexafluoropropylene) for High Energy Density Capacitors with Enhanced Lifetime. J. Polym. Sci. Part B Polym. Phys. 2012, 50 (14), 993-1003.

(20) Brandstetter, S. S.; Drummy, L. F.; Horwath, J. C.; Schweickart, D. L.; Vaia, R.A. Breakdown Voltage of Thermoplastics with Clay Nanometer-Sized Fillers. Proc. IEEE International Power Modulators and High Voltage Conference, 2008, pp 287-290.

(21) Fillery, S. P.; Koerner, H.; Drummy, L.; Dunkerley, E.; Durstock, M. F.; Schmidt, D. F.; Vaia, R. A. Nanolaminates: Increasing Dielectric Breakdown Strength of Composites. ACS Appl. Mater. Interfaces 2012, 4 (3), 1388-1396.

(22) Yoo, H. G.; Byun, M.; Jeong, C. K.; Lee, K. J. Performance Enhancement of Electronic and Energy Devices via Block Copolymer Self-Assembly. Adv. Mater. 2015, 27 (27), 3982-3998.

(23) Anastasiadis, S. H.; Russell, T. P.; Satija, S. K.; Majkrzak, C. F. Neutron Reflectivity Studies of the Surface-Induced Ordering of Diblock Copolymer Films. Phys. Rev. Lett. 
1989, 62 (16), 1852-1855.

(24) Russell, T. P.; Coulon, G.; Deline, V. R.; Miller, D. C. Characteristics of the SurfaceInduced Orientation for Symmetric Diblock PS/PMMA Copolymers. Macromolecules $1989,22,4600-4606$.

(25) Shin, C.; Ahn, H.; Kim, E.; Ryu, D. Y.; Huh, J.; Kim, K. W.; Russell, T. P. Transition Behavior of Block Copolymer Thin Films on Preferential Surfaces. Macromolecules 2008, $41,9140-9145$.

(26) Sinturel, C.; Vayer, M.; Morris, M.; Hillmyer, M. A. Solvent Vapor Annealing of Block Polymer Thin Films. Macromolecules 2013, 46 (14), 5399-5415.

(27) Chen, Z.-R.; Kornfield, J. A.; Smith, S. D.; Grothaus, J. T.; Satkowski, M. M. Pathways to Macroscale Order in Nanostructured Block Copolymers. Science. 1997, 277 (5330), $1248-1253$.

(28) Angelescu, D. E.; Waller, J. H.; Adamson, D. H.; Deshpande, P.; Chou, S. Y.; Register, R. A.; Chaikin, P. M. Macroscopic Orientation of Block Copolymer Cylinders in SingleLayer Films by Shearing. Adv. Mater. 2004, 16 (19), 1736-1740.

(29) Majewski, P. W.; Gopinadhan, M.; Osuji, C. O. Magnetic Field Alignment of Block Copolymers and Polymer Nanocomposites: Scalable Microstructure Control in Functional Soft Materials. J. Polym. Sci. Part B Polym. Phys. 2012, 50 (1), $2-8$.

(30) Thurn-Albrecht, T.; DeRouchey, J.; Russell, T. P.; Kolb, R. Pathways toward Electric Field Induced Alignment of Block Copolymers. Macromolecules 2002, 35 (21), 81068110. 
(31) Böker, A.; Knoll, A.; Elbs, H.; Abetz, V.; Müller, A. H. E.; Krausch, G. Large Scale Domain Alignment of a Block Copolymer from Solution using Electric Fields. Macromolecules 2002, 35, 1319-1325.

(32) Cheng, J. Y.; Mayes, A. M.; Ross, C. A. Nanostructure Engineering by Templated SelfAssembly of Block Copolymers. Nat Mater 2004, 3 (11), 823-828.

(33) Edwards, E. W.; Montague, M. F.; Solak, H. H.; Hawker, C. J.; Nealey, P. F. Precise Control over Molecular Dimensions of Block-Copolymer Domains Using the Interfacial Energy of Chemically Nanopatterned Substrates. Adv. Mater. 2004, 16 (15), 1315-1319.

(34) Modi, A.; Bhaway, S.M.; Vogt, B.D.; Douglas, J.F.; Al-Enizi, A.; Elzatahry, A.; Sharma, A. and Karim, A. Direct Immersion Annealing of Thin Block Copolymer Films. ACS Appl. Mater. Interfaces, 2015, 7(39), 21639-21645.

(35) Singh, G.; Yager, K. G.; Berry, B.; Kim, H. C.; Karim, A. Dynamic Thermal FieldInduced Gradient Soft-Shear for Highly Oriented Block Copolymer Thin Films. ACS Nano 2012, 6 (11), 10335-10342.

(36) Singh, G.; Batra, S.; Zhang, R.; Yuan, H.; Yager, K. G.; Cakmak, M.; Berry, B.; Karim, A. Large-Scale Roll-to-Roll Fabrication of Vertically Oriented Block Copolymer Thin Films. ACS Nano 2013, 7 (6), 5291-5299.

(37) $\mathrm{Xu}$, Ting; Craig J. Hawker; Thomas P. Russell. Interfacial Interaction Dependence of Microdomain Orientation in Diblock Copolymer Thin Films. Macromolecules 2005, 38(7), 2802-2805.

(38) Bates Frank S., Fredrickson, Glenn H. Block Copolymer Thermodyamics: Theory and 
Experiment. Annu. Rev. Phys. Chem. 1990, 41, 525-557.

(39) Sinturel, C.; Bates, F.S.; Hillmyer, M.A. High $\chi$-Low N Block Polymers: How Far Can We Go?. ACS Macro Lett. 2015, 4(9), 1044-1050.

(40) Wolak, M. A., Wan, A. S., Shirk, J. S., Mackey, M., Hiltner, A., \& Baer, E. Imaging the Effect of Dielectric Breakdown in a Multilayered Polymer Film.J. Appl. Polym. Sci., 2012, 123(4), 2548-2557.

(41) Vogelsang, R.; Brutsch, R.; Farr, T.; Frohlich, K. Electrical Tree Propagation along Barrier-Interfaces in Epoxy Resin. Annual Report Conference on Electrical Insulation and Dielectric Phenomena; IEEE, 2002,1, pp 946-950.

(42) Ku, C. C.; Liepins, R. Electrical Properties of Polymers; Hanser Publishers: Munich, 1987.

(43) American Society for Testing and Materials Annual. Philadelphia, PA, USA 1992, Sec., 4, 04-08.

\section{Graphical Table of Contents}
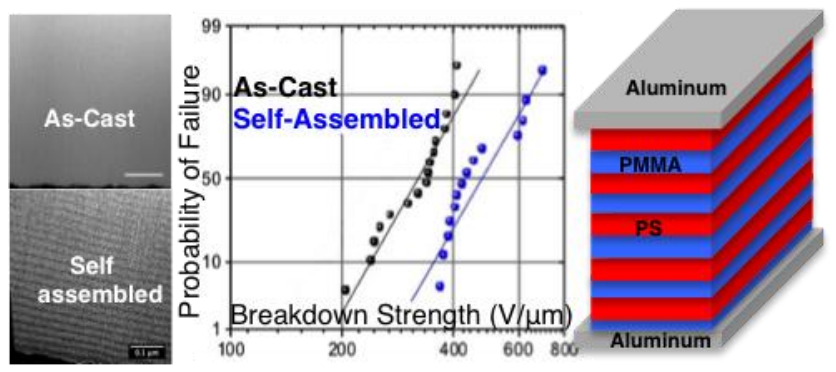